\title{
SIMULATOR POSISI MATAHARI DAN BULAN BERBASIS WEB DENGAN WEBGL
}

\author{
Kamshory* dan Syafii** \\ *Mahasiswa S2 Teknik Elektro Universitas Andalas \\ *Staf Pengajar Teknik Elektro Universitas Andalas
}

\begin{abstract}
Abstrak-Bulan sebagai sebuah satelit bumi mempunyai peranan penting bagi kehidupan bumi. Selain sebagai salah satu sumber penerangan, bulan juga mempunyai pengaruh bagi bumi baik di darat maupun di laut. Pengaruh bulan terhadap bumi berhubungan dengan posisinya. Penelitian ini bertujuan membuat simulator posisi matahari dan bulan terhadap bumi berdasarkan waktu dan lokasi pengamatan. Simulator dibuat berbasis web dalam 3 dimensi (3D) dengan menggunakan teknologi webGL. Posisi matahari dan bulan dinyatakan dengan lintang dan bujur yang merupakan posisi yang dilewati oleh garis yang menghubungkan bumi dengan matahari atau garis yang menghubungkan bumi dengan bulan. Posisi matahari dan bulan didapatkan dari perhitungan berdasarkan penelitian sebelumnya. Setelah posisi tersebut diketahui, bumi, matahari, dan bulan digambarkan sebagai model 3 dimensi. Posisi kamera dapat dipindahkan dengan men-drag halaman web sehingga matahari, bumi, dan bulan dapat dilihat dari berbagai posisi. Kamera selalu mengarah ke pusat bumi untuk menghindari kesalahan pengguna memindah-mindahkan kamera yang menyebabkan objek tidak terlihat.
\end{abstract}

Kata kunci: matahari, bumi, bulan, sudut deklinasi, fase bulan, sistem waktu, delta T, webGL

\begin{abstract}
Moon as a satellite of the earth has an important role for the life of the earth. Apart from being a source of illumination, moon also has an effect on the earth both on land and at sea. The influence of the moon to the earth relate to the its position. This research aims to create a simulator of the sun and moon position to the earth based on the time and location of the observation. This simulator is web-based and made in 3-dimensional (3D) using webGL technology. The position of the sun and moon expressed by latitude and longitude which is a position that is passed by the line connecting the earth to the sun or the line connecting the earth to the moon. The position of the sun and moon obtained from calculations based on previous research. Once the position is known, the earth, the sun, and the moon then described as a 3-D model. The position of the camera can be moved by dragging a web page so that the sun, earth, and moon can be seen from various positions. The camera always leads to the center of the earth to avoid user errors flipping the camera which causes the object is not visible.
\end{abstract}

Keywords: sun, earth, moon, declination angle, moon phase, time systems, delta T, webGL

\section{PENDAHULUAN}

\subsection{Latar Belakang}

Bulan sebagai satelit bumi digunakan sebagai acuan dalam beberapa sistem penanggalan. Contoh sistem penanggalan yang menggunakan bulan sebagai acuannya antara lain adalah Yahudi, Romawi, Celts dan Jerman. Penanggalan Islam adalah penanggalan bulan yang paling banyak digunakan saat ini. (Longstaff, 2005)

Bulan merupakan benda langit yang terdekat dengan bumi yang memiliki massa yang cukup besar. Dengan demikian, bulan dapat mempengaruhi resultan gaya gravitasi di suatu tempat di muka bumi. Dampak dari perubahan resultan gaya gravitasi ini antara lain adalah pasang surut air laut. Selain itu, perubahan resultan gaya ini juga mempengaruhi hasil pengukuran berat dengan timbangan yang menggunakan pegas atau sensor berat.

Posisi bulan dapat digunakan untuk melakukan perhitungan terhadap pengaruh gaya gravitasi bulan sehingga dapat digunakan untuk menentukan pasang surut air laut serta untuk mengoreksi kesalahan penimbangan. Posisi bulan ini didapatkan bukan dengan pengamatan langsung namun dilakukan dengan menggunakan perhitungan. 
Posisi bulan juga dapat mempengaruhi hasil timbangan yang tidak menggunakan bandul karena perubahan resultan gaya gravitasi yang diterima oleh benda yang diukur.

Lebih jauh lagi, Eckhard Etzold pada tahun 2005 melakukan penelitian pengaruh bulan purnama terhap kejiwaan. Penelitian ini diperkuat oleh penelitian-penelitian sebelumnya tentang pengaruh bulan purnama pada prilaku manusia. Penelitian tersebut antara lain dilakukan oleh C. Bördlein pada tahun 2002; R.Culver, J. Rotton, \& I. W. Kelly pada tahun 2002 serta E. Wunder \& M. Schardtmüller pada tahun 2002. (Etzold, 2005)

Karena begitu banyaknya pengaruh posisi bulan terhadap bumi, maka diperlukan sebuah simulator yang dapat menggambarkan posisi matahari dan bulan pada waktu dan tempat tertentu. Simulator yang berjalan berbasis web lebih mudah untuk dijalankan oleh semua orang tanpa harus memasang aplikasi tambahan pada komputer pengguna.

\subsection{Tujuan Penelitian}

Tujuan penelitian ini adalah sebagai berikut:

1. Sebagai salah satu acuan dalam menentukan pergantian bulan Hijriyah

2. Sebagai salah satu acuan untuk menentukan pasang surut air laut berdasarkan posisi bulan dan matahari pada tempat dan waktu tertentu

\subsection{Manfaat Penelitian}

Salah satu manfaat penelitian ini adalah untuk membantu menentukan pergantian bulan Hijriyah baik dengan metode hisab maupun ru'yat. Metode ru'yat juga membutuhkan perhitungan karena apabila bulan tidak terlihat di ufuk barat, maka bilangan tanggal digenapkan menjadi 30. Bilangan 30 ini tentu saja didapatkan dari hasil perhitungan. Selain untuk menentukan pergantian bulan Hijriyah, penelitian ini juga bermanfaat bagi pengembang perangkat lunak untuk menentukan pasang surut air laut. Dengan mengetahui posisi matahari dan bulan pada sembarang tempat dan waktu, maka pengembang dapat dengan mudah untuk menguji algoritma programnya tanpa harus melakukan survey ke lapangan dengan waktu berbulan-bulan. Program juga bermanfaat bagi dunia pendidikan yaitu sebagai sebuah alat peraga untuk mempermudah dalam menjelaskan tentang posisi matahari dan bulan terkait dengan fenomena alam seperti gerhana dan pasang surut.

\section{TINJAUAN PUSTAKA}

\subsection{Delta T}

Sebelum membahas mengenai Delta $\mathrm{T}$ atau $\Delta \mathrm{T}$, terlebih dahulu harus dipahami bahwa sistem waktu Universal Time (UT) bukanlah sistem waktu yang seragam. Universal Time atau UT didasarkan pada rotasi bumi (Meeus, 1991). Di sisi lain, kecepatan rotasi bumi secara umum mengalami perlambatan dengan ketidakteraturan yang tidak dapat diperkirakan (Meeus, 1991).

Untuk perhitungan astronomi dibutuhkan sebuah sistem waktu yang seragam yang tidak terpengaruh oleh rotasi bumi (Meeus, 1991). Dengan demikian, dibuatlah sebuah sistem waktu yang seragam seperti Internation Atomic Time atau TAI, Terrestrial Dynamic Time atau TDT, dan Barycentric Dynamic Time atau TDB. TDT dan TDB memiliki perbedaan waktu 0,0017 detik. Akan tetapi, TDT dan TDB dapat disederhanakan menjadi Dynamic Time atau TD (Meeus, 1991). Perbedaan antara TD dengan UT disebut dengan $\Delta \mathrm{T}$ yang dihitung dengan persamaan sebagai berikut (Meeus, 1991):

$$
\Delta T=T D-U T
$$

Nilai pasti dari $\Delta \mathrm{T}$ dihitung dari pengamatan (Meeus, 1991). Akan tetapi, untuk keperluan perhitungan astronomi diperlukan nilai $\Delta \mathrm{T}$ yang didapat dari prediksi.

\subsection{Persamaan Waktu}

Persamaan waktu digunakan untuk mengetahui waktu matahari transit dan sudut deklinasi matahari pada waktu dan tempat 
tertentu. Setelah waktu transit dan sudut deklinasi diketahui, waktu matahari terbit, matahari terbenam, dan tengah malam juga dapat dihitung. Jika perhitungan dilakukan dengan sistem waktu Terrestrial Dynamic Time atau TDT, maka diperlukan konversi ke dalam sistem waktu Universal Time agar dapat digunakan oleh sipil.

Algoritma persamaan waktu adalah sebagai berikut:

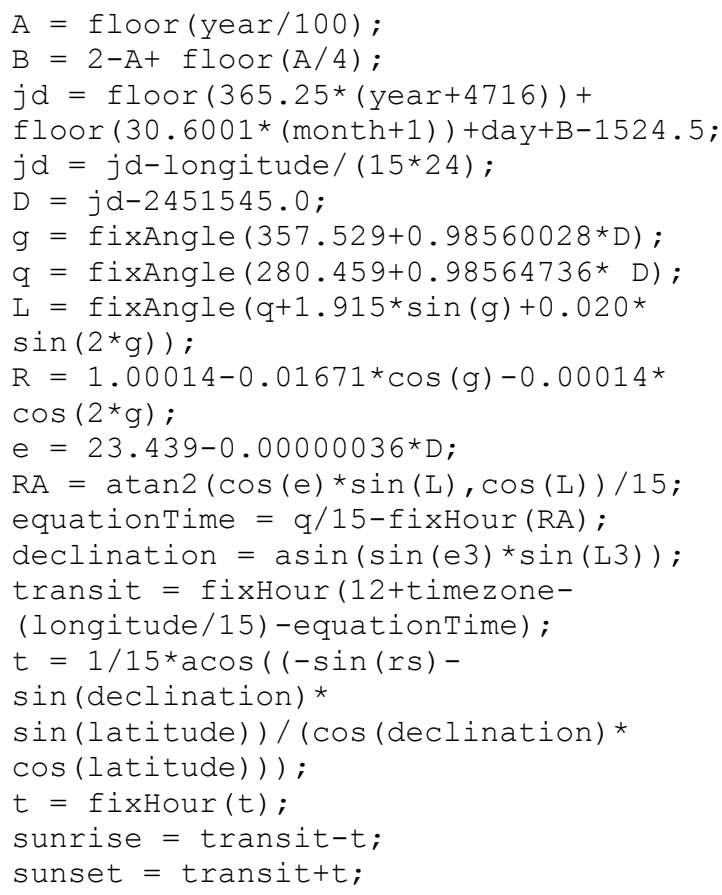

Sudut dinyatakan dalam derajat. Fungsi fixAngle akan memperbaiki sudut dalam derajat sehingga nilainya berada di dalam rentang 0 hingga 360. Fungsi fixHour akan memperbaiki bilangan jam sehingga nilainya berada di dalam rentang 0 hingga 24 .

Sudut deklinasi dinyatakan dalam derajat yang merupakan lintang dari bumi. Sudut positif untuk di posisi sebelah utara khatulistiwa dan sudut negatif untuk daerah di sebelah selatan khatulistiwa.

Waktu matahari terbit (sunrise), transit, dan matahari terbenam (sunset) dinyatakan dalam jam dengan bilangan ril. Untuk mendapatkan nilai menit dan detik, bilangan jam tersebut dikonversi dengan algoritma sebagai berikut:

t1 = parseInt (real);

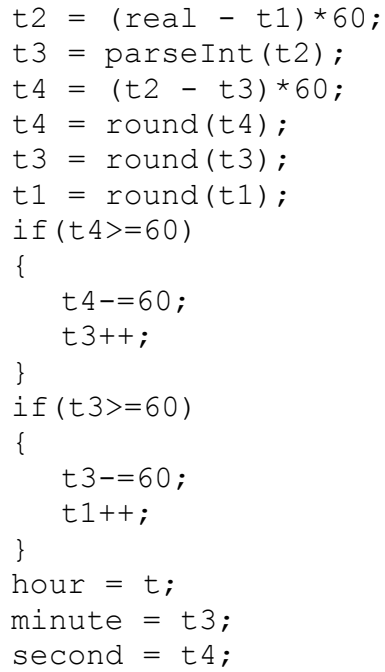

\subsection{Fase Bulan}

Fase bulan adalah fase yang dihitung berdasarkan berapa bagian bulan yang mendapat cahaya matahari jika dilihat dari bumi. Nilai fase berkisar antara 0 dan 1 . Fase 0 adalah fase di mana bulan baru dimulai sedangkan fase 0,5 adalah fase di mana terjadinya bulan purnama. Setelah tanggal tua, nilai fase akan mendekati 1 namun tidak pernah sama dengan 1 karena fase 1 berarti fase 0 di bulan berikutnya (Mathews, Cornell, \& Rasista, 2006).

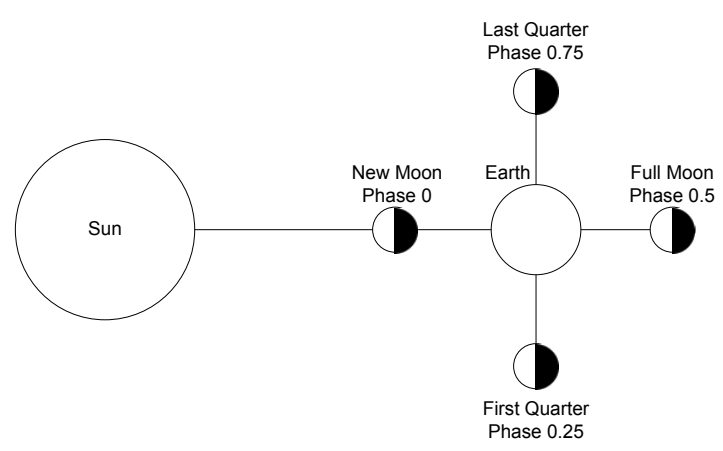

Gambar 1 Fase Bulan

\subsection{Sudut Deklinasi Bulan}

Sudut deklinasi bulan disebabkan karena lintasan revolusi bulan mengelilingi bumi tidak sejajar dengan garis khatulistiwa. Dengan periode sideris bulan lebih kurang 27,32 hari, maka sudut deklinasi akan berulang selama waktu itu pula. 
Algoritma untuk menghitung sudut deklinasi bulan adalah sebagai berikut:

$\mathrm{t}=$ days / 36525;

M1 = fixAngle $(357.529+35999 * t$ -

$0.0001536 * t * t+t * t * t / 24490000)$;

$\mathrm{L} 1=$ fixAngle $(280.466+36000.8 * \mathrm{t}) ;$

$\mathrm{C} 1=(1.915-0.004817 * t-0.000014 *$

$t * t) * \sin (M 1)$;

$\mathrm{C} 1=\mathrm{C} 1+(0.01999-0.000101 * t) *$

$\sin (2 * \mathrm{M} 1)$

$\mathrm{C} 1=\mathrm{C} 1+0.00029 * \sin (3 * \mathrm{M} 1) ;$

$\mathrm{Th} 1=\mathrm{L} 1+\mathrm{C} 1$.

Obl $=(84381.448-46.815 * t) / 3600 ;$

$\operatorname{Dec} 1=\operatorname{asin}(\sin (0) * \cos (\mathrm{Ob} l)+$

$\left.\cos (0){ }^{*} \sin (O b I) * \sin (\operatorname{Th} 1)\right)$;

(http://www.lunar-

occultations.com/rlo/ephemeris.htm, diakses

tanggal 27 Agustus 2015 pukul 6:57 WIB)

\section{METODOLOGI PENELITIAN}

\subsection{Garis Besar Perancangan Sistem}

Sistem dibuat berbasis web dan dapat berjalan pada semua browser web yang mendukung webGL. Adapun blok diagram dari sistem diperlihatkan pada gambar 1.

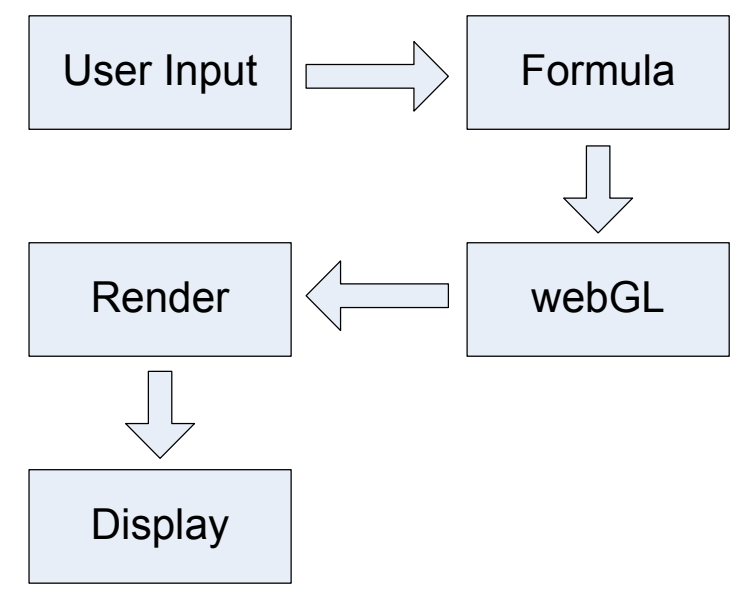

Gambar 2 Blog Diagram Penelitian

\subsection{Perangkat Keras}

Perangkat keras yang digunakan adalah sebuah komputer pribadi atau PC yang dilengkapi dengan monitor dan imput berupa keyboard serta pointing device berupa mouse atau touchpad. Adapter grafis yang mendukung webGL dibutuhkan untuk mengolah gambar 3 dimensi.

\subsection{Perangkat Lunak}

Perangkat lunak yang digunakan berupa

1. Sistem operasi yang mendukung webGL

2. Browser web yang mendukung JavaScript dan webGL

\subsection{Perancangan Perangkat Lunak}

Perangkat lunak sistem berupa file HTML, CSS, dan JavaScript. HTML merupakan dokumen utama untuk menampilkan halaman web. CSS merupakan dokumen untuk mengatur tampilan web. JavaScript merupakan program untuk melakukan perhitungan serta sebagai Application Programming Interface (API) untuk webGL.

File dapat disimpan di dalam hardisk untuk dibuka langsung oleh browser web dan dapat pula disimpan di dalam sebuah server web untuk dibuka dari komputer lain melalui jaringan baik Local Area Network (LAN) atau internet menggunakan browser web.

Sistem menerima masukan berupa waktu, lokasi pengamatan, dan daerah waktu yang digunakan. Waktu dan lokasi tersebut akan menjadi parameter dalam perhitungan posisi matahari dan bulan. Hasil perhitungan tersebut digunakan sebagai parameter untuk posisi matahari dan bulan. Titik koordinat 0,0,0 merupakan titik pusat bumi sehingga titik koordinat matahari dan bulan sesuai dengan posisi lintang dan bujur matahari dan bulan. Karena sistem koordinat pada webGL adalah sistem koordinat kartesian 3 dimensi, maka diperlukan konversi dari sistem koordinat bola ke sistem koordinat kartesian.

Sistem juga menerima masukan dari pengguna untuk menentukan posisi kamera sehingga browser web dapat menampilkan gambar sesuai dengan posisi kamera yang dipilih. Penentuan posisi kamera juga menggunakan sistem koordinat bola. Lintang kamera ditentukan dari perubahan cursor pada saat pengguna melakukan drag secara vertikal, bujur kamera ditentukan dari perubahan cursor pada saat pengguna melakukan drag 
secara horizontal, sedangkan jarak kamera dengan titik pusat ditentukan dari scroll. Ketiga parameter tersebut selanjutnya dikonversi ke dalam sistem koordinat kartesian untuk menentukan posisi kamera. Kamera tetap menghadap ke titik $0,0,0$ atau pusat bumi.

Program membuat garis antara pusat bumi dan pusat matahari dengan warna merah, pusat bumi dan pusat bulan dengan warna biru, serta membuat garis vertikal dengan warna hijau yang menunjukkan titik pengamatan.

\section{HASIL DAN PEMBAHASAN}

grafik 3 dimensi serta data dalam bentuk angka yang ditampilkan pada layar. Tampilan program ditunjukkan pada gambar 3 dan gambar 4.

Program menampilkan gambar bumi, matahari, dan bulan. Sudut pandang dapat diubah dengan cara memindahkan posisi kamera. Pemindahan kamera dilakukan dengan cara men-drag halaman web serta memutar scroll mouse. Aksi ini mengubah lintang dan bujur kamera serta jarak antara kamera ke titik pusat bumi. Parameter ini diubah menjadi koordinat $\mathrm{x}, \mathrm{y}$, dan $\mathrm{z}$ kamera. Posisi kamera juga ditampilkan pada program.

\subsection{Hasil Pengujian Sistem}

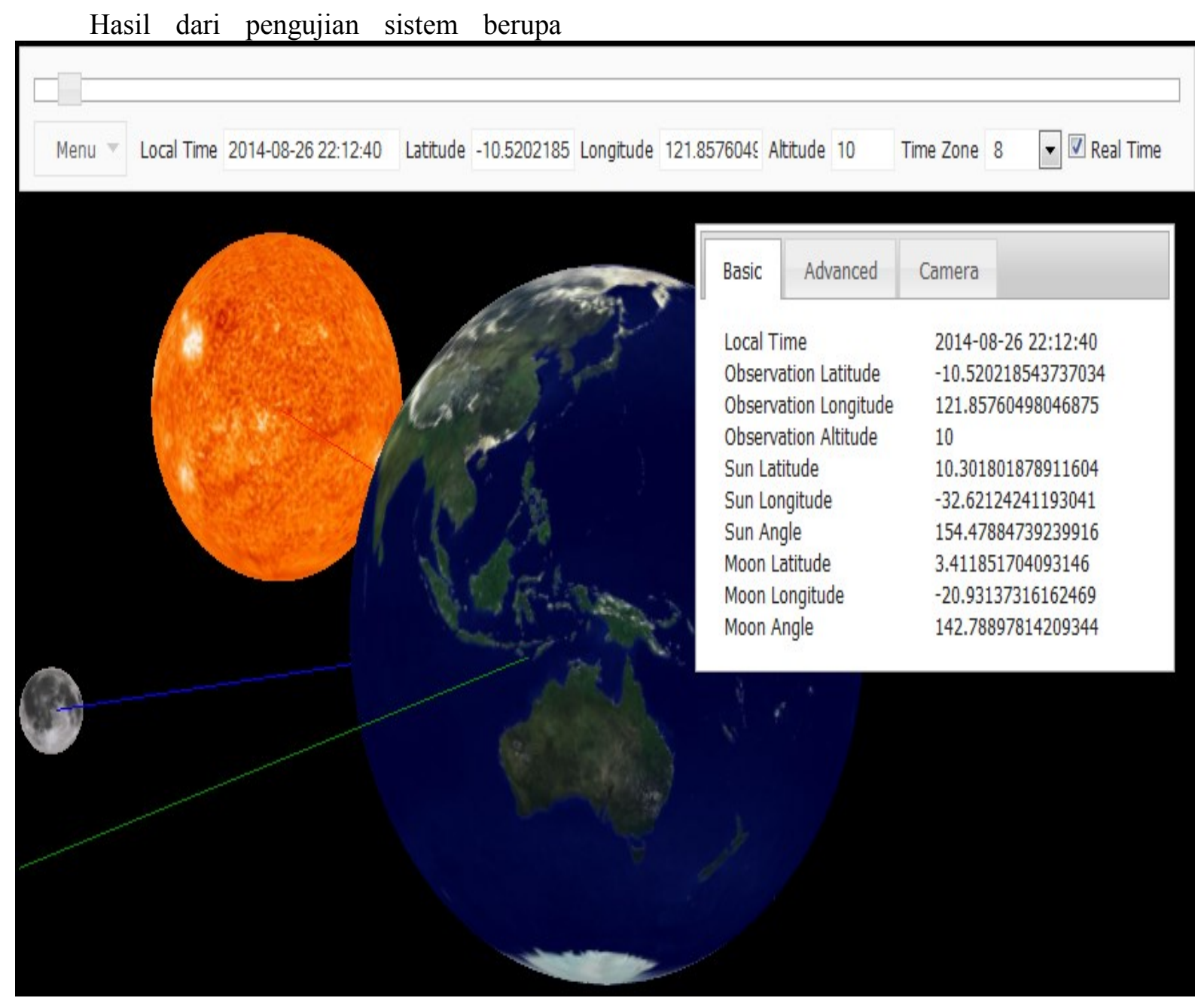

Gambar 3 Tampilan Program dengan Posisi Matahari dan Bulan 


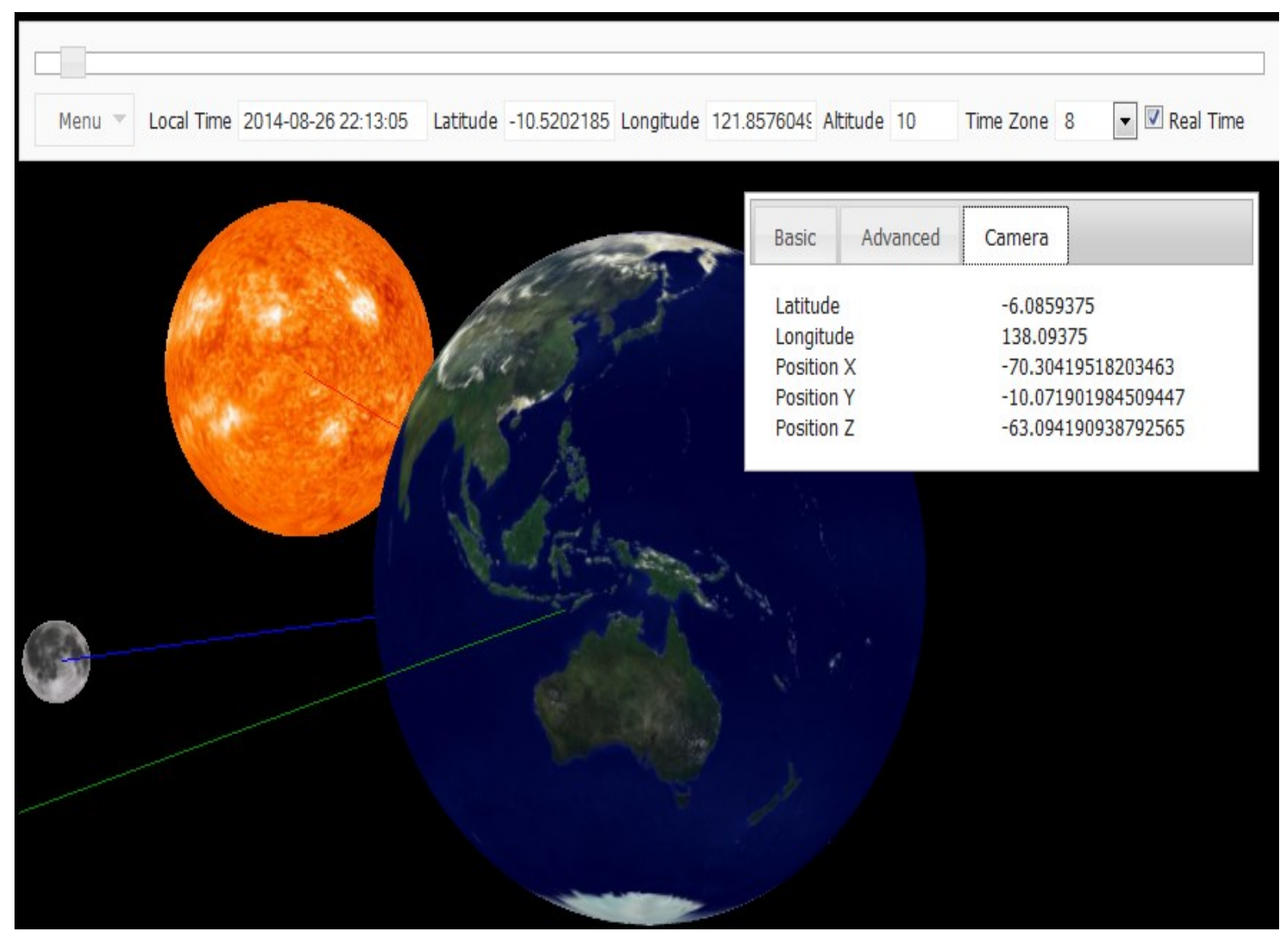

Gambar 4 Tampilan Program dengan Posisi Kamera

Pengujian perhitungan dilakukan dengan membandingkan informasi waktu pada fasefase bulan sepanjang tahun 2014 yang dihasilkan oleh program dengan informasi yang diberikan pada situs web National Aeronautics and Space Administration (NASA).

Tabel 1 Perbandingan Hasil Perhitungan Fase Bulan antara Program dengan NASA

\begin{tabular}{|l|l|l|l|l|l|l|l|}
\hline New Moon & \multicolumn{3}{|l|}{ First Quarter } & \multicolumn{2}{l|}{ Full Moon } & \multicolumn{2}{l|}{ Qast Quarter } \\
\hline NASA & Program & NASA & Program & NASA & Program & NASA & Program \\
\hline Jan 1 06:14 & Jan 1:06:14 & Jan 7 22:39 & Jan 7 22:39 & Jan 15 23:52 & Jan 15 23:52 & Jan 24 00:19 & Jan 24 00:20 \\
\hline Jan 30 16:39 & Jan 30 16:39 & Feb 6 14:22 & Feb 6 14:21 & Feb 14 18:53 & Feb 14 18:54 & Feb 22 12:15 & Feb 14 12:16 \\
\hline Mar 1 03:00 & Mar 1 03:02 & Mar 8 08:27 & Mar 8 08:26 & Mar 16 12:09 & Mar 16 12:10 & Mar 23 20:46 & Mar 23 20:47 \\
\hline Mar 30 13:45 & Mar 30 13:47 & Apr 7 03:31 & Apr 7 03:31 & Apr 15 02:42 & Apr 15 02:44 & Apr 22 02:52 & Apr 22 02:52 \\
\hline Apr 29 01:14 & Apr 29 01:16 & May 6 22:15 & May 6 22:16 & May 14 14:16 & May 14 14:18 & May 21 07:59 & May 21 07:59 \\
\hline May 28 13:40 & May 28 13:42 & Jun 5 15:39 & Jun 5 15:40 & Jun 12 23:11 & Jun 12 23:13 & Jun 19 13:39 & Jun 19 13:39 \\
\hline Jun 27 03:09 & Jun 27 03:09 & Jul 5 06:59 & Ju1 5 07:00 & Jul 12 06:25 & Jun 12 06:26 & Jul 18 21:08 & Ju1 18 21:09 \\
\hline Ju1 26 17:42 & Ju1 26 17:42 & Aug 3 19:50 & Aug 3 19:50 & Aug 10 13:09 & Aug 10 13:10 & Aug 17 07:26 & Aug 17 07:26 \\
\hline Aug 25 09:13 & Aug 25 09:12 & Sep 2 06:1 & Sep 2 06:11 & Sep 8 20:38 & Sep 8 20:38 & Sep 15 21:05 & Sep 15 21:05 \\
\hline Sep 24 01:14 & Sep 24 01:13 & Oct 1 14:33 & Oct 1 14:32 & Oct 8 05:51 & Oct 8 05:50 & Oct 15 14:12 & Oct 15 14:12 \\
\hline Oct 23 16:57 & Oct 23 16:55 & Oct 30 21:48 & Oct 30 21:48 & Nov 6 17:23 & Nov 6 17:22 & Nov 14 10:16 & Nov 14 10:16 \\
\hline
\end{tabular}




\begin{tabular}{|l|l|l|l|l|l|l|l|}
\hline New Moon & \multicolumn{3}{|l|}{ First Quarter } & \multicolumn{2}{l|}{ Full Moon } & \multicolumn{2}{l|}{ Quarter } \\
\hline NASA & Program & NASA & Program & NASA & Program & NASA & Program \\
\hline Nov 22 07:32 & Nov 22 07:31 & Nov 29 05:06 & Nov 29 05:06 & Dec 6 07:27 & Dec 6 07:26 & Dec 14 07:51 & Dec 14 07:53 \\
\hline Dec 21 20:36 & Dec 21 20:35 & Dec 28 13:31 & Dec 28 13:32 & & & & \\
\hline
\end{tabular}

Dari tabel 1 terlihat bahwa terjadi perbedaan waktu antara hasil yang didapatkan oleh perhitungan program dengan data NASA. Perbedaan tersebut paling besar adalah 2 menit. Pada fase bulan yang terdapat perbedaan data dari NASA dan dari program diberi warna abu-abu untuk memudahkan pembacaan.

\section{KESIMPULAN}

1. Program mampu menampilkan posisi matahari dan bulan secara 3 dimensi untuk waktu dan tempat tertentu.

2. Posisi kamera dapat dipindahkan sehingga program dapat menampilkan objek dari arah tertentu

3. Perbedaan hasil perhitungan waktu fase bulan antara program dengan NASA paling besar adalah 2 menit.

\section{DAFTAR PUSTAKA}

\section{Buku dan Jurnal}

1. Etzold, E. (2005). Solar-Periodic Full Moon Effect in The Fourmilab Retropsychokinesis Project Experiment Data: An Exploratory Study. The Journal of Parapsychology, 233.

2. Longstaff, A. (2005). Calendars from Around the World. Greenwich: National Maritime Museum.

3. Mathews, S. M., Cornell, K. F., \& Rasista, B. A. (2006). Where is the Moon Tonight? The National Council Teachers of Mathematics, Inc. , 467.

4. Meeus, J. (1991). Astronomical Algorithms. Richmond: Willman-Bell, Inc.

5. Situs Web Approximate Moon physical ephemeris in Javascript http://www.lunaroccultations.com/rlo/ephemeris.htm

6. Astronomical Times http://www.cv.nrao.edu/ rfisher/Ephemerid es/times.html

7. NASA - Delta $T$ http://eclipse.gsfc.nasa.gov/LEcat5/deltat.ht $\mathrm{ml}$

8. NASA - Polynomial Expressions for Delta $\mathrm{T}$

http://eclipse.gsfc.nasa.gov/LEcat5/deltatpo ly.html

9. Harmonic Analysis and Prediction of Tides http://www.math.sunysb.edu/ tony/tides/ha rmonic.html

10. Global

University http://certificate.ulo.ucl.ac.uk/modules/year _one/ROG/moon/conWebDoc.8028.html

11.Lunar Perigee and Apogee Calculator oleh John Walker (http://www.fourmilab.ch/earthview/pacalc. html)

\section{Biodata Penulis}

Kamshory lahir di Jambi tahun 1983, memperoleh gelar S.T dari Jurusan teknik elektro Universitas Andalas Padang dan saat ini sedang menempuh pendidikan S2 pada Jurusan Teknik Elektro Universitas Andalas. 